\title{
DESERTIFICATION ASSESSMENT USING MEDALUS MODEL IN UPPER LAMCHIENGKRAI WATERSHED, THAILAND
}

\author{
S. Plaiklang ${ }^{1, *}$, I. Sutthivanich ${ }^{2}$, T. Sritarapipat ${ }^{2}$, K. Panurak $^{3}$, S. Ogawa ${ }^{4}$, S. Charungthanakij ${ }^{5}$, U. Maneewan ${ }^{2}$, N. Thongrueang $^{1}$. \\ ${ }^{1}$ Rambhaibarni Rajabhat University, Chanthaburi, Thailand - (sasikarn.p, nutnaree.t)@ rbru.ac.th \\ ${ }^{2}$ Suranaree University of Technology, Nakhon Ratchasima, Thailand - (suttin1, tanakorn.s, udomvit)@ sut.ac.th \\ ${ }^{3}$ Huathalae Subdistrict Municipality, Nakhon Ratchasima - kanyarki@gmail.com \\ ${ }^{4}$ Institute of Spatial Technology, Tokyo, Japan - ogawa_susumu_phd@yahoo.co.jp \\ ${ }^{5}$ Silpakorn University, Nakhon Pathom, Thailand - kanyarki@gmail.com
}

KEY WORDS: Desertification, MEDALUS, Upper Lamchiengkrai Watershed

\begin{abstract}
:
Desertification is a global environmental problem. It affects harmful on economic, social and environmental that ultimately effects on quality of human life. Thailand is the 174th member of the UNCCD, according to the Thailand report of desertification by LDD (2004). It was found that the area of degraded land or desertification land in Thailand was 33.57 million hectares which were agricultural soil problem. Soil erosion and soil salinity are major problems for agricultural soil in Thailand. Thus, to prevent and fix such problems, assessment and evaluation of soil properties are essential. Lamchiengkrai watershed in Nakhon Ratchasima province presents soil salinity exposure area which is a major problem in the Northeast region of Thailand. This study aims to access a new approach for assessing the extent and the risk of desertification land by MEDALUS model based on geoinformatics technology in upper Lamchiengkrai watershed, Nakhon Ratchasima province. MEDALUS model is the factors of desertification assessment. Four groups of factors were examined, including vegetation (fire risk, erosion protection, and drought resistance), climatic (rainfall and rainfall erosivity), soil (soil texture, electrical conductivity, organic matter, soil depth, drainage, and slope), and human activity factor (land use and soil erosion). The results of the study indicated that $67.25 \%$ of the area was classified as high risk, $30.54 \%$ was classified as moderate risk and $2.22 \%$ was classified as low risk to desertification land. In addition, the factors affected on the highrisk area were climate and vegetation factors. Moderate risk area was influenced by the human activity factor and soil factors.
\end{abstract}

\section{INTRODUTION}

Desertification is a global environmental problem (Anuluxtipun, 2017). It has harmful impacts on economic, social and environmental that ultimately affect human sustenance and quality of life. The United Nations Convention to Combat Desertification (UNCCD) defined the desertification as "land degradation in arid, semi-arid and dry sub-humid areas resulting from various factors, including climatic variations and human activities" (FAO, 1993; Wijitkosum, 2016). According to the definition of the United Nations Convention to Combat Desertification, Thailand is classified as an affected country although it is located in a monsoon climate (LDD, 2004). Thailand is the 174th member of the United Nations Convention to Combat Desertification (UNCCD). According to the Thailand report of desertification by LDD (2004), it was found that the area of degraded land or desertification land in Thailand was 33.57 million hectares of problem soils for agriculture. Anuluxtipun (2017) stated that 6.93 Million rai of the area in Thailand $(2.17 \%)$ severely impact of desertification in Thailand. The causes of desertification are human activities that affected the desertification including high population and poverty, inappropriate cultivating techniques, deforestation, ill-adopted legal frameworks, weak management capacity, lack of adequate knowledge, and lack of awareness in the local population (Hai et al., 2013). The unsustainable land use may lead to soil degradation which is known as desertification (Núñez et al., 2012; Cebecauer et al.,2008). LDD (2004) stated that the major causes of desertification found in Thailand are: (a) climatic factors (heavy rain during the monsoon period dissolves and translocate soil minerals and seasonal drought); (b) human activities (land use without soil improvement, over-exploitation of land, land use on steep slope lands causing soil erosion and expansion of saline soils). Soil erosion and soil salinity are major problems for soils for agriculture in Thailand (Katawatin and Sukchan, 2012). There is numerous techniques has been used for the desertification assessment such as observation and measurement, mathematical models and parametric equations, estimates, remote sensing (RS) and other indicators (Rubio and Bochet, 1998; Ladisa, Todorovic, Liuzzi, 2012). Anuluxtipun (2017) indicated that the desertification in Thailand has been studied to allocate the potential drought hazard areas and early warning for arable land. Consequently, to prevent and fix such problems, Thailand needs implementation. This study aims to study a new approach for assessing the extent and the risk of desertification land by Mediterranean Desertification and Land Use (MEDALUS) based on geoinformatics technology in upper Lamchiengkrai watershed of Nakhon Ratchasima province in Thailand. This area represents the soil salinity exposure area which is major problems in the Northeast region of Thailand. MEDALUS model is the factors of desertification assessment must take in considerations of AGENDA 21 and UNCCD. The Study examined four groups of factors: vegetation (fire risk, erosion protection, and drought resistance), climatic (rainfall and rainfall erosivity), soil (soil texture, electrical conductivity, organic matter, soil depth, drainage, and slope), and human activity factor (land use and soil erosion) for evaluation.

\footnotetext{
* Corresponding author
} 


\section{MATERIALS AND METHODS}

\subsection{Study Area}

The study area was a part of Upper Lamchiengkrai watershed which originated from the mountainous area in Bamnet Narong district, Chaiyaphum province. It locates in Nakhon Ratchasima province. The study area covered the area of 464.96 sq. $\mathrm{km}$. (Figure 1).

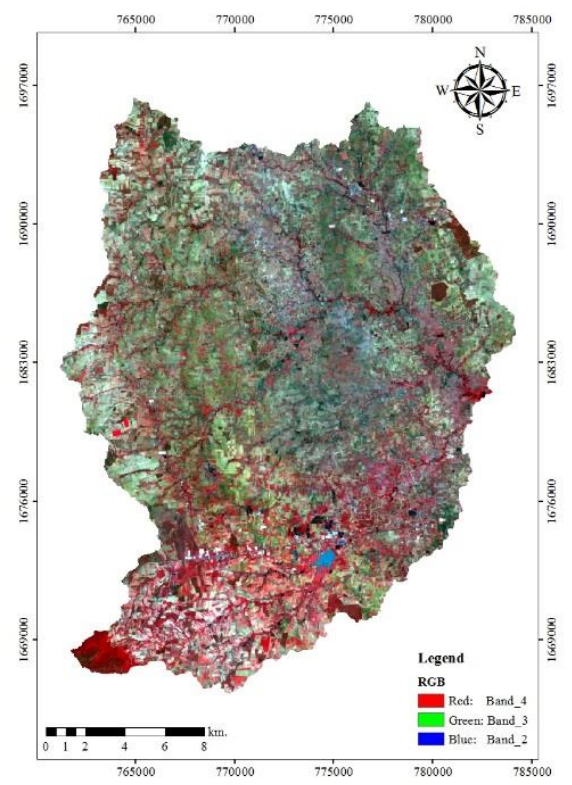

Figure 1. Landsat 8 data of the study area

\subsection{Scope of the study}

1. Land use and land cover data in 2015 are extracted from Landsat data, spectral indices, and bio-physical factors based on an optimum decision tree with CRT algorithm and based on the study of Plaiklang (2017).

2. Soil erosion, soil salinity and organic matter content in this study are based on the study of Plaiklang (2017).

\subsection{Limitations of this study}

This study utilizes available spatial and non-spatial data for desertification assessment. Thus, the accuracy of desertification assessment depends on the accuracies of the available data.

\subsection{Research methodology}

We use the methodbased on the original model of MEDALUS, developed in a large project established by the European Commission (Faraizadeh and Eqbal, 2007). The MEDALUS is one of the most widely used models in monitoring desertification sensitivity. Several studies were based on it, especially in Euro-Mediterranean countries. In Thailand, which was less numerous, were conducted to assess desertification, namely these of Wijitkosum on the premises of the Huay Sai Royal Development Study Centre, in Petchaburi (Wijitkosum, 2016), and Anuluxtipun used the similar model for Thailand (Anuluxtipun, 2017).

The MEDALUS identifies the environmentally sensitive areas and involves soil, vegetation, climate, and human activity indicators. Each indicator is represented by an index which is calculated by the combination of sub-indexes. The output map corresponds to desertification sensitivity areas (Benabderrahmane and Chenchouni, 2010).

Research methodology was designed to serve the main objectives of the research included (1) data collection and preparation, (2) to assess soil quality index (SQI), (3) to assess vegetation quality index (VQI), (4) to assess climate quality index (VQI), (5) to assess human activity quality index (HQI), and (6) to assess desertification risk.

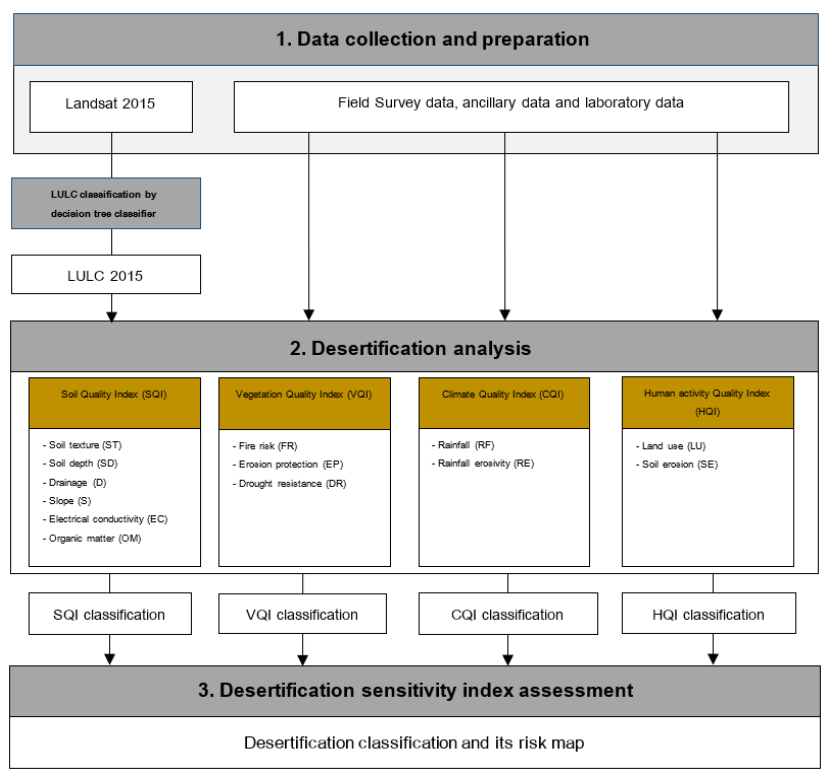

Figure 2. Workflow diagram of the research methodology.

\section{Component 1: Data Collection and Preparation}

In this study, we used data set included remotely sensed data, GIS data and field survey data. We used equipment for soil survey included soil core, GPS and digital camera.

\section{Component 2: Desertification analysis}

1. Soil Quality Index Assessment

Soil quality index (SQI) contained six correlated parameters: soil texture (ST), soil depth (SD), drainage (DR), slope (S), electrical conductivity (EC), and organic matter content (OM), was processed by using ESRI ArcGIS environment (Figure 13). The parameters are linked with drought and desertification. The soil is the important factor which can be related to water availability, erosion resistance and capacity to sustain the growth and maintenance of vegetation. Also, the slope is a crucial factor in the processes of soil erosion (Kosmas, Ferrara, Briasouli, and Imeson, 1999).

The algebraic expression reflecting the effect of soil factor is given by Equation (1):

$$
\mathrm{SQI}=(\mathrm{ST} * \mathrm{SD} * \mathrm{DR} * \mathrm{~S} * \mathrm{EC} * \mathrm{OM}) 1 / 5
$$

Where SQI is the soil quality index; ST is the soil texture, SD is the soil depth (SD), D is the drainage (DR), $\mathrm{S}$ is the slope, EC is the electrical conductivity, and $\mathrm{OM}$ is the organic matter content.

The sub-indexes ST, SD, and D were created from soil series map of LDD in 1999. Slope parameter was derived from a digital elevation model of USGS in 2014. EC and OM data were created from previous studies of Plaiklang (2017). All the variables correspond to weights (Table1) and are dimensionless. 
(2) Vegetation Quality Index Assessment

The VQI was assessed in three aspects: Fire risk, Erosion protection, Drought resistance. The algebraic expression reflecting the effect of vegetation indicators is given by Equation (2):

$$
\mathrm{VQI}=(\mathrm{FR} * \mathrm{EP} * \mathrm{DR}) 1 / 3
$$

Where VQI is the vegetation quality index; FR is the fire risk, $\mathrm{EP}$ is the erosion protection, and DR is the drought resistance. The sub-indexes all parameters were created by land use 2015 and correspond to weights (Table 1).

(3) Climate Quality Index Assessment

The CQI in the MEDALUS model was aimed to assess water availability at the plantation. Two parameters were used to access CQI: rainfall and rainfall erosivity. The algebraic expression reflecting the effect of climate indicators is given by Equation (2):

$$
\mathrm{CQI}=(\mathrm{RF} * \mathrm{RE}) 1 / 2
$$

Where CQI is the climate-quality index; RF is the rainfall and $\mathrm{RE}$ is the rainfall erosivity.

The sub-indexes the rainfall was created by surface interpolation from mean rainfall data of TMD in 2015. The rainfall erosivity was derived from rainfall erosivity equation. All the parameters correspond to weights (Table 1).

(4) Human Activity Quality Index Assessment

The HQI was assessed in two aspects: land use and soil erosion. Soil erosion in the study areas was caused by human activities which affected land use and management.

$$
\mathrm{HQI}=(\mathrm{LU} * \mathrm{SE}) 1 / 2
$$

Where HQI is the human activities quality index; LU is the land use and SE are the soil erosion.

The sub-indexes all parameters were generated from ancillary data of previous studies of Plaiklang (2017) and all parameters correspond to weights (Table 1).

Component 3: Desertification Sensitivity Index Assessment In this section, multiple indicators (SQI, COI, VQI, and HQI) were combined using the multiplicative method for soil degradation evaluation. In this section, the quality indices were computed and employed in the GIS model for computing the DSI and for mapping the desertification sensitivity map. The Desertification Sensitivity Index (DSI) assessment was computed as a function of the SQI, CQI, VQI, and HQI as shown in Eq. (5):

$$
\mathrm{DSI}=(\mathrm{SQI} * \mathrm{COI} * \mathrm{VQI} * \mathrm{HQI}) 1 / 4
$$

The mapping of the desertification sensitivity map was analyzed by integrating the analyses of both spatial and attribute data. Integration, management, and processing of data were performed using processing under ESRI ArcGIS environment. The scoring and classification categories of the indices for mapping are shown in Table 2 . The severity of desertification was classified as high severe, severe, moderate or low severe (Wijitkosum, 2016; Sepehr, Hassanli, Ekhtesasi, and Jamali, 2007). Based on the estimated DSI values, the classes of

\begin{tabular}{|c|c|c|c|c|}
\hline Indicators & $\begin{array}{l}\text { Sub indicators } \\
\text { (layers) }\end{array}$ & Quantitative & \begin{tabular}{|l|} 
Qualitative \\
\end{tabular} & Class \\
\hline Soil quality & $\begin{array}{l}\text { Texture } \\
\text { Slope }(\%) \\
\text { Soil depth (cm) } \\
\text { Drainage } \\
\text { Electrical } \\
\text { conductivity (EC) } \\
\text { Organic matter (OM) }\end{array}$ & $\begin{array}{l}<1.13 \\
1.13-1.45 \\
>1.46\end{array}$ & \begin{tabular}{|l} 
Low \\
Medium \\
High
\end{tabular} & $\begin{array}{l}\text { S1 } \\
\text { S2 } \\
\text { S3 }\end{array}$ \\
\hline $\begin{array}{l}\text { Climate } \\
\text { quality }\end{array}$ & $\begin{array}{l}\text { Rainfall } \\
\text { Rainfall erosivity }\end{array}$ & $\begin{array}{l}1 \\
1.1-1.5 \\
1.6-2\end{array}$ & $\begin{array}{l}\text { Low } \\
\text { Medium } \\
\text { High }\end{array}$ & $\begin{array}{l}\text { C1 (Humid) } \\
\text { C2 (Semi- } \\
\text { arid) } \\
\text { C3 (Arid) }\end{array}$ \\
\hline $\begin{array}{l}\text { Vegetation } \\
\text { quality }\end{array}$ & $\begin{array}{l}\text { Fire Risk } \\
\text { Erosion protection } \\
\text { Drought resistance }\end{array}$ & $\begin{array}{l}<1.13 \\
1.13-1.38 \\
>1.38\end{array}$ & \begin{tabular}{|l|} 
Low \\
Medium \\
High
\end{tabular} & $\begin{array}{l}\text { V1 } \\
\text { V2 } \\
\text { V3 }\end{array}$ \\
\hline $\begin{array}{l}\text { Human } \\
\text { activity } \\
\text { quality }\end{array}$ & $\begin{array}{l}\text { Water erosion } \\
\text { Land use }\end{array}$ & $\begin{array}{l}1 \\
1-1.4 \\
1.4-2\end{array}$ & $\begin{array}{l}\text { Low } \\
\text { Medium } \\
\text { High }\end{array}$ & $\begin{array}{l}\mathrm{H} 1 \\
\mathrm{H} 2 \\
\mathrm{H} 3\end{array}$ \\
\hline
\end{tabular}
desertification sensitivity in the area can be shown in Table 3 .

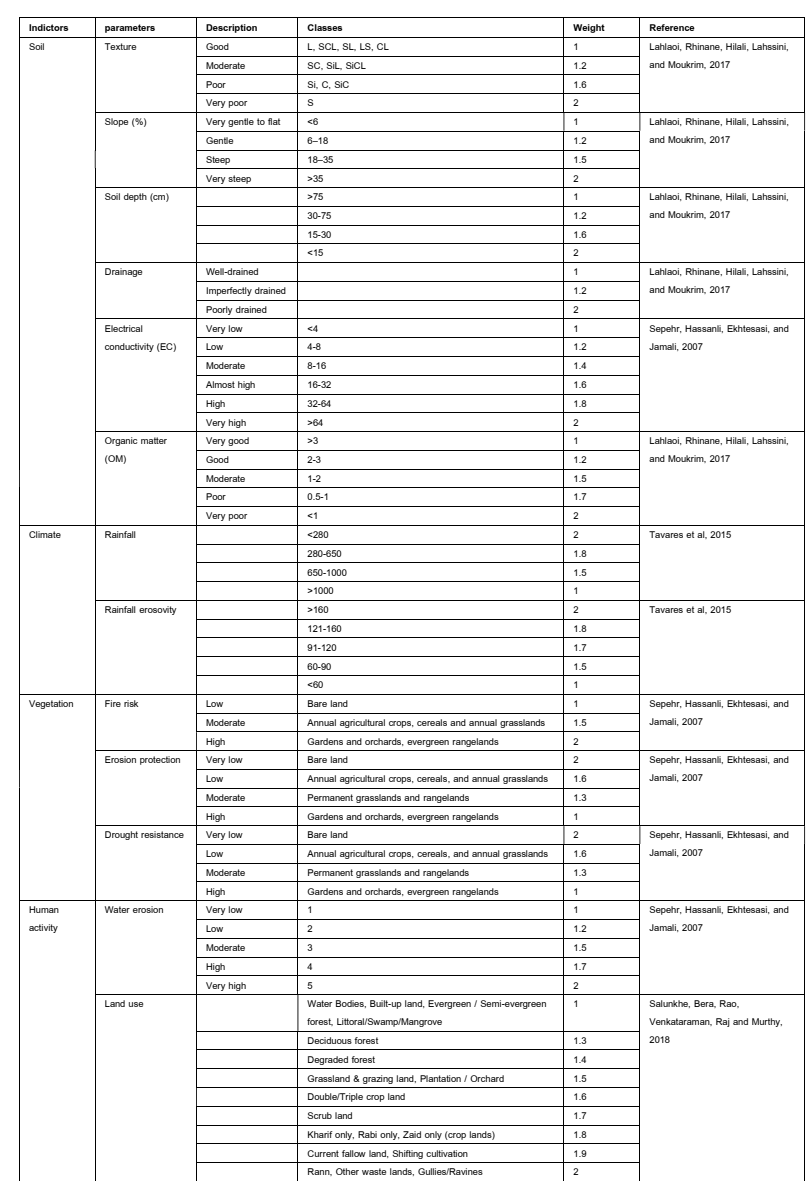

Table 1. Classes and assigned weighting index for parameters

Table 2. Quantitative scores and qualitative classes of considered indicators (indices)

\begin{tabular}{|c|c|c|c|}
\hline Class & DSI & Sensitivity area to desertification & Risk \\
\hline 1 & $1.00-1.22$ & Low & Low \\
\hline 2 & $1.23-1.37$ & Moderate & Moderate \\
\hline 3 & $1.38-1.53$ & High & High \\
\hline 4 & $1.54-2.00$ & Very high & Severe \\
\hline
\end{tabular}

Table 3. Ranges and classes of desertification sensitivity index (DSI) (Wijitkosum, 2016).

\section{RESULTS AND DISCUSSION}

\subsection{Data Collection and Preparation}

Remotely sensed data and bio-physical data were collected and prepared for analysis and modelling and are shown in Table 4 In this study, Landsat 8 data, Path 129 and Row 49, acquired date 9 March 2015 was downloaded from the USGS website (www.earthexplorer.usgs.gov). 


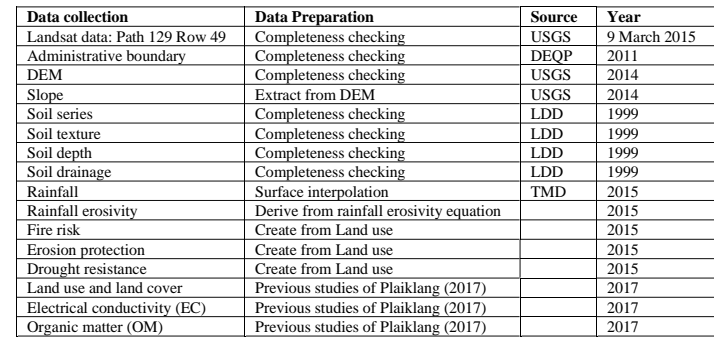

Table 4. List of data collection and preparation

\subsection{Soil Quality Index Assessment and its severity}

The result of the soil quality index and its severity in 2015 with the MEDALUS model is further reclassified its severity as suggestion by Wijitkosum (2016); Lahlaoi, Rhinane, Hilali, Lahssini, and Moukrim (2017); Sepehr, Hassanli, Ekhtesasi, and Jamali, (2007) as shown in Figure 4 while area and percentage of soil quality index classification is summarized in Table 5. As a result, the dominant soil quality index classes in the study area are low and it covers an area of $332.02 \mathrm{sq}$. $\mathrm{km}$ or about $71.41 \%$ of the total study area. Besides, the soil quality assessment in this study is similar to the previous work of Wijitkosum (2016), who applied the soil texture and the soil fertility factors for soil quality index assessment and both the soil texture factor and the soil fertility factor had low-level effects on the desertification risk in the Pa Deng area.

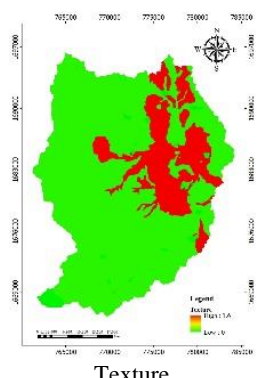

Texture

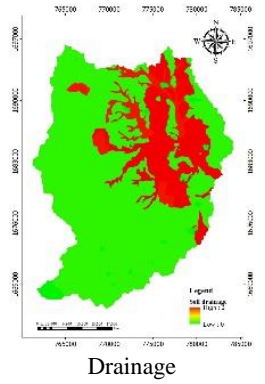

, tow

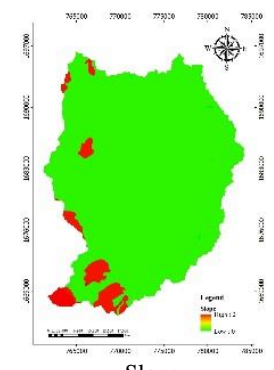

Slope
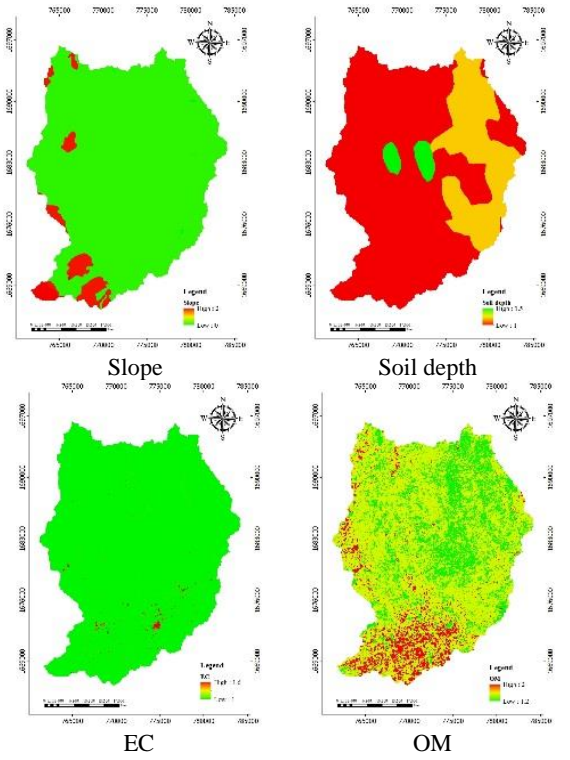

Figure 3 Soil quality index factors.
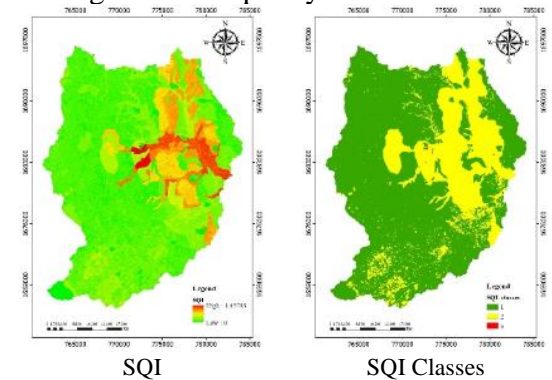

Figure 4 The distribution of soil quality index classification.

\begin{tabular}{|l|l|l|l|l|l|l|}
\hline Indicators & Sub-indicators (layers) & Range & Class & SQI classes & Sq.km. & $\%$ \\
\hline $\begin{array}{l}\text { Soil } \\
\text { quality }\end{array}$ & $\begin{array}{l}\text { Texture } \\
\text { Slope }(\%) \\
\text { Soil depth (cm) }\end{array}$ & 1.13 & S1 & Low & 332.02 & 71.41 \\
\cline { 2 - 8 } & \begin{tabular}{l} 
Drainage \\
Electrical conductivity (EC) \\
\cline { 5 - 8 }
\end{tabular} & $>1.46$ & S2 & Moderate & 132.86 & 28.57 \\
\hline
\end{tabular}

Table 5. Quantitative scores and qualitative classes of soil indicators.

\subsection{Vegetation Quality Index Assessment and its severity} As a result, it was found that vegetation quality index and its severity in 2015 with MEDALUS model is further reclassified its severity as a suggestion by Sepehr, Hassanli, Ekhtesasi, and Jamali (2007) as shown in Figure 6 while area and percentage of vegetation quality index classification are summarized in Table 6 . The dominant vegetation quality index classes are high risk and it covers an area of $419.38 \mathrm{sq}$. km or about $90.20 \%$ of the total study area. In addition, the vegetation quality assessment in this study is similar with the previous work of Boudjemline and Semar (2018) who applied the erosion protection, fire risk, drought resistance, and plant cover factors for vegetation quality index assessment and all factors had highlevel effects on the desertification risk the mostly area of the basin of Hodna in Algeria (35.26\%).

\begin{tabular}{|l|l|l|l|l|l|l|}
\hline Indicators & Sub-indicators (layers) & Range & Class & $\begin{array}{l}\text { VQI } \\
\text { classes }\end{array}$ & Sq.km. & $\%$ \\
\hline \multirow{2}{*}{$\begin{array}{l}\text { Vegetation } \\
\text { quality }\end{array}$} & $\begin{array}{l}\text { Fire Risk } \\
\text { Erosion protection } \\
\text { Drought resistance }\end{array}$ & $<1.13$ & V1 & Low & 0.00 & 0.00 \\
\cline { 2 - 7 } & & $>1.13-1.38$ & V2 & Moderate & 45.58 & 9.80 \\
\hline
\end{tabular}

Table 6. Quantitative scores and qualitative classes of vegetation indicators
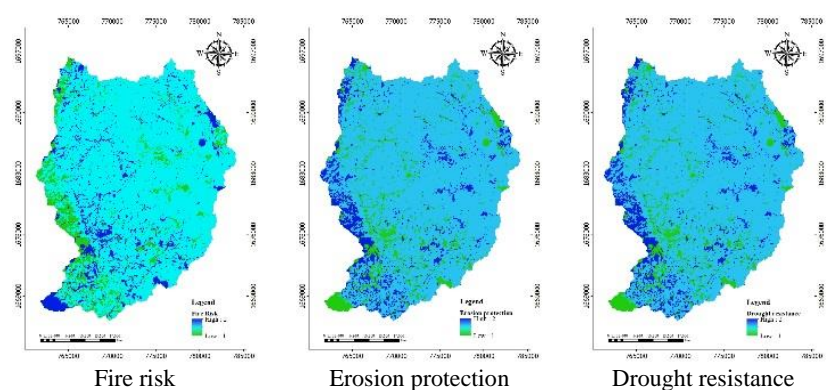

Figure 5. Vegetation quality index factors
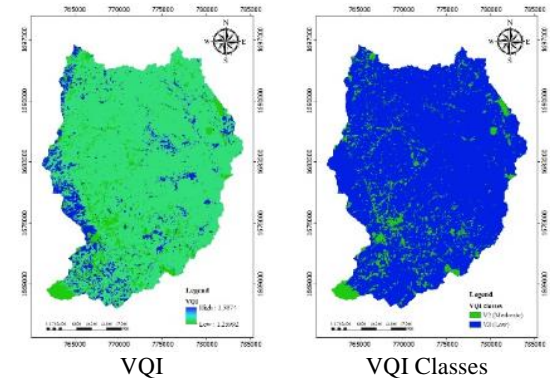

Figure 6. The distribution of vegetation quality index classification.

\subsection{Climate Quality Index Assessment and its severity}

As a result, it appeared that climate quality index and its severity in 2015 with MEDALUS model is further reclassified its severity as a suggestion by Tavares et al (2015) as shown in Figure 8 while area and percentage of climate quality index classification are summarized in Table 7 . The dominant climate quality index classes are high risk and it covers an area of 351.16 sq. $\mathrm{km}$ or about $75.53 \%$ of the total study area. In addition, the climate-quality assessment is similar to the past work of Boudjemline and Semar (2018) who applied the annual precipitation, aridity, field orientation factors for climate-quality index assessment and all factors had high-level effects on the desertification risk the mostly area of the basin of Hodna in Algeria (61.87\%). 


\begin{tabular}{|c|c|c|c|c|c|c|}
\hline \multirow{3}{*}{$\begin{array}{l}\text { Indicators } \\
\text { Climate } \\
\text { quality }\end{array}$} & Sub-indicators (layers) & Range & Class & CQI classes & Sq.km. & $\%$ \\
\hline & \multirow{3}{*}{$\begin{array}{l}\text { Rainfall } \\
\text { Rainfall erosivity }\end{array}$} & \multirow{3}{*}{$\begin{array}{l}1 \\
1.1-1.5 \\
1.6-2\end{array}$} & C1 (Humid) & Low & 0.00 & \\
\hline & & & C2 (Semi-arid) & Moderate & 113.80 & 24.47 \\
\hline $\begin{array}{l}\text { Climate } \\
\text { quality }\end{array}$ & & & C3 (Arid) & High & 351.16 & 75.53 \\
\hline
\end{tabular}

Table 7. Quantitative scores and qualitative classes of climate indicators.
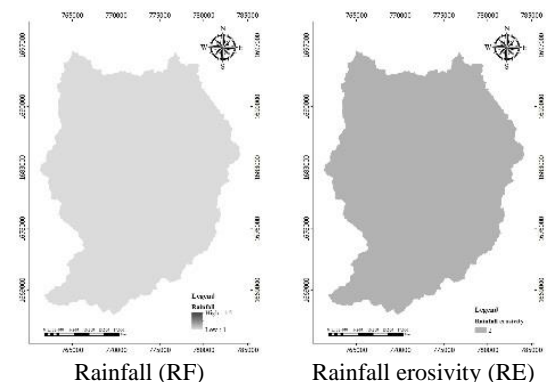

Figure 7. Climate quality index factors.
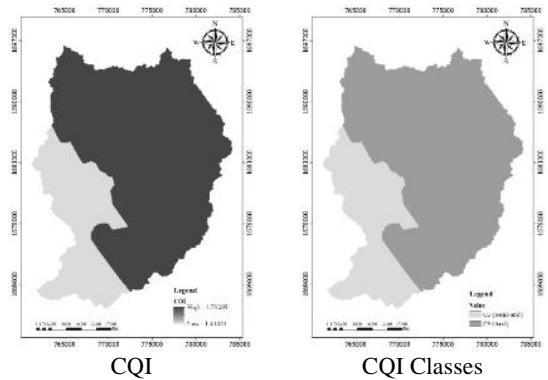

Figure 8 . The distribution of climate quality index classification.

\subsection{Human Activity Quality Index Assessment and its} severity

As a result, it was noted that human activity quality index and its severity in 2015 with the MEDALUS model is further reclassified its severity as suggestion by Sepehr, Hassanli, Ekhtesasi, and Jamali (2007); Wijitkosum (2016); Salunkhe, Bera, Rao, Venkataraman, Raj and Murthy (2018) as shown in Figure 10 while area and percentage of human activity quality index classification is summarized in Table 8. The dominant human activity quality index classes are high risk and it covers an area of 438.49 sq. $\mathrm{km}$ or about $94.31 \%$ of the total study area. In addition, the human activity quality assessment is similar to the previous work of Lahlaoi, Rhinane, Hilali, Lahssini, and Moukrim (2017) who applied the grazing, the population density, and the conservation practices for human activity quality index assessment and all factors had moderately level effects on the desertification risk of the mostly area of Oued El Maleh watershed in Morocco (71.22\%).

\begin{tabular}{|l|l|l|l|l|l|l|}
\hline Indicators & Sub indicatorslayers) & Range & Class & HQI classes & Sq.km. & $\%$ \\
\hline \multirow{2}{*}{$\begin{array}{l}\text { Human } \\
\text { activity } \\
\text { quality }\end{array}$} & \multirow{2}{*}{ Water erosion } & 1 & H1 & Low & 23.49 & 5.05 \\
\cline { 3 - 8 } & & $1-1.4$ & H2 & Moderate & 438.49 & 94.31 \\
\cline { 3 - 8 } & & $1.4-2$ & H3 & High & 2.98 & 0.64 \\
\hline
\end{tabular}

Table 8. Quantitative scores and qualitative classes of Human activity quality indicators.
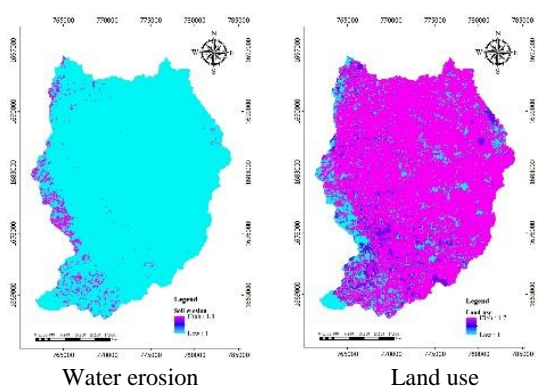

Figure 9. Human activity quality index factors
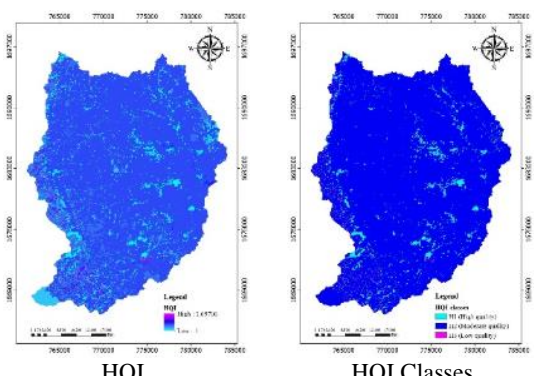

Figure 10. The distribution of human activity index classification

\subsection{Desertification Sensitivity Index Assessment}

The study of the desertification risk in the study area, classified the severity of the desertification risk into three levels: low; moderate; high risk. The derived desertification risk is further classified its severity according to Wijitkosum (2016) as shown in Figure 11. The area and percentage of desertification sensitivity index classification are presented in Table 9. 1
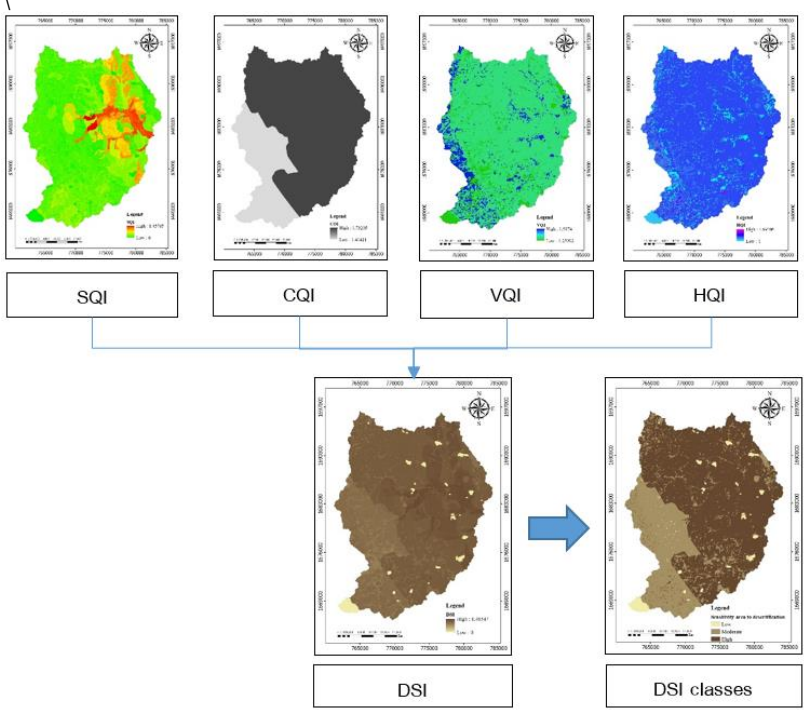

Figure 11. the distribution of desertification sensitivity index classification.

\begin{tabular}{|c|c|c|c|c|}
\hline Class & DSI & $\begin{array}{c}\text { Sensitivity area to } \\
\text { desertification (Risk) }\end{array}$ & Sq.km. & $\%$ \\
\hline 1 & $1.00-1.22$ & Low & 10.24 & 2.20 \\
\hline 2 & $1.23-1.37$ & Moderate & 143.85 & 30.94 \\
\hline 3 & $1.38-1.53$ & High & 310.86 & 66.86 \\
\hline \multicolumn{3}{|c|}{ Total } & 464.96 & 100.00 \\
\hline
\end{tabular}

Table 9. Severity classes of desertification sensitivity index (DSI) 


\section{CONCLUSIONS}

Desertification is an irreversible process of soil degradation. It impacts on economic, social and environmental that ultimately affects human sustenance and quality of life.

The methodology is based on the use of the MEDALUS model. The model includes four factors; soil, vegetation, climate, and human activity. Each factor is assessed by the combination of sub-factors first and then combined to assess desertification classes and its risk.

The study findings indicate that $67.25 \%$ of the area is classified as high-risk, $30.54 \%$ as moderate risk and $2.22 \%$ as lowly affected by desertification land. In addition, the high risk area is affected by the climate factors $(75.53 \%)$ and vegetation factors $(71.41 \%)$ and $94.31 \%$ of the human activity factor is classified as moderately affected and $71.41 \%$ of the soil factors are classified as moderately affected by desertification area in this study.

In conclusion, it appears that application of geoinformatics technology can be used as an efficient tool to assess soil quality index and its severity, to assess vegetation quality index and its severity, to assess climate quality index and its severity, to assess human activity quality index and its severity, for desertification risk area assessment. It can save cost, time, and quickly assess data. It is expected that the approach will greatly benefit to another area which faces similar desertification risk area problems.

\section{RECOMMENDATION}

Many objectives were here investigated and implemented, the possibly expected recommendations could be made for further studies as following.

(1) For the MEDALUS model, some input factors of the MEDALUS model were acquired from the literature review. Therefore, more field measurement is recommended for the input factors in order to achieve the realistic model results and it should validate the model from data collection of the field.

(2) Desertification risk assessment should be tested in another area that faces similar desertification risk problems for verification and validation of the method.

\section{REFERENCES}

LDD., 2004: Kingdom of Thailand National Action Programme for Combating Desertification. Land Development Department Ministry of Agriculture and Cooperatives, March 2004.

Anuluxtipun, Y., 2017: Climate Change Effect on Rice and Maize Production in Lower Mekong Basin. Journal of Geoinformation Technology of Burapha University, 2(3).

FAO., 1993: Sustainable development of dry lands and combating desertification http://www.fao.org/docrep/ V0265E/V0265E00.htm. (1 August 2012).

Wijitkosum, S., 2016: The impact of land use and spatial changes on desertification risk in degraded areas in Thailand. Sustainable Environment Research 26 (2016) 84-92.

Hai LT, Gobin A, Hens L., 2013: Risk assessment of desertification for Binh Thuan province, Vietnam. Human and Ecological Risk Assessment: An International Journal, 19 (6): 1544-56.

Núñez M, Civit B, Muñoz P, Arena AP, Rieradevall J, Antón A., 2010: Assessing potential desertification environmental impact in life cycle assessment Part 1: Methodological aspects. The International Journal of Life Cycle Assessment, 15(1): 67-78.

Cebecauer T, Hofierka J., 2008: The consequences of landcover changes on soil erosion distribution in Slovakia. Geomorphology, 98(3-4): 187-98.

Katawatin, R., Sukchan, S., 2012: Mapping Soil Salinity and Soil Erosion in Thailand. Pedologist. 343-354.

Rubio JL, Bochet E., 1998: Desertification indicators as diagnosis criteria for desertification risk assessment in Europe. J Arid Environ; 39:113e20.

Ladisa G, Todorovic M, Liuzzi GT., 2012: A GIS-based approach for desertification risk assessment in Apulia region, SE Italy. Phys Chem Earth, 49:103e13.

Faraizadeh, M.; Eqbal, M.N., 2007: Evaluation of MEDALUS Model for Desertification Hazard Zonation Using GIS; Study Area: IyzadKhast Plain, Iran. Pak. J. Biol. Sci., 10, 2622-2630.

Benabderrahmane, M.C.; Chenchouni, H., 2010: Assessing Environmental Sensitivity Areas to Desertification in Eastern Algeria using Mediterranean Desertification and Land Use "MEDALUS" Model. Int. J. Sustain. Water Environ. Syst., 1, 5-10.

Plaiklang, S., 2017: Application of geoinformatics for soil degradation assessment in Upper Lamchiengkrai watershed, Nakhon Ratchasima province, Thailand.

Kosmas, C.; Ferrara, A.; Briasouli, H.; Imeson, A., 1999: Methodology for Mapping Environmentally Sensitive Areas (ESAs) to Desertification. In The Medalus Project Mediterranean Desertification and Land Use. Manual on Key Indicators of Desertification and Mapping Environmentally Sensitive Areas to Desertification;

Lahlaoi, H., Rhinane, H., Hilali, A., Lahssini, S., Moukrim, S., 2017: Desertification Assessment Using MEDALUS Model in Watershed Oued El Maleh, Morocco. Geosciences. Geosciences, 7(50).

Sepehr, A., Hassanli, A. M., Ekhtesasi, M. R., Jamali, J. B., 2007: Quantitative assessment of desertification in south of Iran using MEDALUS method. Environ Monit Assess. Environ Monit Assess.

Tavares, Baptista, Ferreira, Amiotte-Suchet, Coelho, Gomes, Amoros, Reis, Mendes, Costa, Bentub, Catena, 2015: Assessment and mapping of desertification sensitivity in an insular sahelian mountain region - case study of the Ribeira Seca Watershed, Cape Verde. Catena, 128, 214-223.

Salunkhe, S. S, Bera, A. K., Rao, S. S., Venkataraman, V. R., Raj, U., MURTHY, Y V N. K., 2018: Evaluation of indicators for desertification risk assessment in part of Thar Desert Region of Rajasthan using geospatial techniques. J. Earth Syst. Sci., 127(116).

Boudjemline, F., Semar, A., 2018: Assessment and mapping of desertification sensitivity with MEDALUS model and GIS - Case study: basin of Hodna, Algeria. Journal of water and land development, 36 (I-III): 17-26.

Lahlaoi, H., Rhinane, H., Hilali, A., Lahssini, S., Moukrim, S., 2017: Desertification Assessment Using MEDALUS Model in Watershed Oued El Maleh, Morocco. Geosciences, 7(50). 